\title{
O estudo da aquisição de inferências pragmáticas como elemento na escolha entre modelos teóricos em disputa
}

\author{
The study of the acquisition of pragmatic inferences as an element in the \\ choice between theoretical models in dispute
}

Marcos Goldnadel

Universidade Federal do Rio Grande do Sul - Porto Alegre, RS, Brasil

Resumo: Fenômeno de comportamento ambivalente, pressuposição tem desafiado algumas gerações de linguistas em relação a dois problemas complementares: o problema da projeção de pressuposições e o problema da origem das pressuposições. Embora o problema descritivo da projeção tenha recebido maior atenção, não se pode lidar com ele sem assumir algum posicionamento quanto ao problema explanatório, relativo à origem das inferências consideradas pressuposicionais. O desacordo que se observa quanto à descrição da projeção de pressuposições contrasta, no entanto, com um relativo consenso, historicamente construído, sobre a natureza das pressuposições. Segundo esse consenso, pressuposição é fenômeno de natureza convencional, sujeito, apenas em sua projeção, a injunções de ordem conversacional. Mais recentemente, esse consenso tem sido abalado por uma nova onda de trabalhos, que, de diversos modos, passaram a defender a ideia de que pressuposição é fenômeno de natureza fundamentalmente conversacional. Entre essas propostas, uma que merece atenção pela plausibilidade é a que identifica pressuposição com implicatura de quantidade escalar. As duas formas de encarar a origem de pressuposições, no entanto, permitem realizar predições distintas quanto ao seu processamento. Interessados na comprovação de uma das duas hipóteses, estudos experimentais foram conduzidos recentemente com a finalidade de avaliar o modo como pressuposições e implicaturas escalares são processadas. Os resultados desses estudos têm sido importante elemento no debate sobre o problema explanatório da origem de pressuposições. Este artigo revisita alguns experimentos que avaliam o modo como ocorre o processamento de implicaturas escalares e pressuposições e procura avaliar a importância, no quadro mais geral desse debate, de trabalhos que investiguem o modo como sujeitos em fase de aquisição processam inferências pragmáticas. Mostra, nesse percurso, que as evidências obtidas podem ser vistas como elementos de apoio a certos modelos ou, alternativamente, como pistas para o aprimoramento das suposições dos modelos que, inicialmente, parecem problematizar.

Palavras-chave: Pressuposição; Implicatura de quantidade escalar; Processamento de inferências pragmáticas; Aquisição de inferências pragmáticas

\begin{abstract}
Phenomenon known for its ambivalent behavior, presupposition has been challenging some generations of linguists regarding two complementary problems: the presupposition projection problem and the problem about the source of presuppositions. Although the descriptive problem has received more attention, it is impossible to cope with it without assuming some position regarding the explanatory problem, associated to the source of presuppositional inferences. The noticeable divergence related to the presupposition projection descriptions is in contrast, however, to a certain consensus, historically built, about the nature of presuppositions. According to this consensus, presupposition is a conventional phenomenon, affected only in its projection by conversational linguistic aspects. Recently, that consensus has been shaken by a new wave of researches that, in different ways, has started to advocate the idea that presupposition is a phenomenon essentially conversational. Among those proposals, it deserves attention for its plausibility the one that associate presupposition to scalar quantity implicature. Both forms to take into account presuppositions, nevertheless, allow different predictions regarding their processing patterns. Focused on the confirmation of one of these hypothesis, some experimental studies had been carried out in order to assess how presuppositions and scalars implicatures are processed. The results obtained have been an important part in the discussion about the explanatory problem of presuppositions. This article revisits some experiments that explore the processing of presuppositions and scalar implicatures, and try to appreciate the importance, in the general context of the debate, of the works which investigate the way subjects in the acquisition stage process pragmatic inferences. What it shows is that the evidences obtained may be seen as supporting some models or, alternatively, as clues aimed to the improvement of the models which they, at a first glance, seems to falsify.
\end{abstract}

Keywords: Presupposition; Scalar quantity implicature; Pragmatic inferences processing; Pragmatic inferences acquisition 


\section{Introdução}

Como toda ciência, a Linguística se constitui a partir de modelos teóricos elaborados para explicar e descrever fenômenos. Embora a preocupação com aspectos descritivos seja essencial, a face explanatória dos modelos, nem sempre mencionada, constitui questão importante. O movimento estruturalista, por exemplo, embora seja considerado o primeiro a abordar a linguagem verbal sob uma perspectiva científica, pouco refletiu sobre questões de natureza explanatória. Preocupava ao linguista desse movimento descrever a estrutura das línguas a partir do reconhecimento de seus constituintes mínimos e de seu modo de organização. Não se encontra nos trabalhos publicados por autores estruturalistas, no entanto, preocupação com a abordagem de questões de caráter explanatório. A língua é vista como entidade socialmente estruturada, mas nenhum fundamento de natureza sociológica, por exemplo, é invocado com o objetivo de identificar as motivações mais profundas para a sua constituição como objeto de análise. Ao contrário, o estruturalismo costuma colocar o aspecto social da linguagem fora de suas preocupações, considerando tudo o que é relativo à fala, face social da língua, como resíduo assistemático, e, por isso, avesso a tratamento científico.

A preocupação com aspectos explanatórios, no entanto, não tardou a ocupar a reflexão linguística. De um lado, surgiu o gerativismo, anunciando como parte de seu projeto a explicação da linguagem verbal enquanto objeto biologicamente determinado. Com isso, rumou em direção a uma reflexão de natureza explanatória, procurando identificar princípios subjacentes à organização dos sistemas linguísticos no terreno da Biologia e das ciências cognitivas. De outro, surgiu a Sociolinguística, voltando-se para a compreensão da variabilidade inerente aos sistemas linguísticos. Nesse movimento, passou a buscar determinantes de natureza social, fundamentando sua abordagem no terreno da Sociologia. Gerativismo e Sociolinguística são duas entre tantas correntes teóricas que buscaram, a partir de fundamentos mais sólidos, explicar a constituição de seus objetos de estudo.

Numa perspectiva mais ampla, portanto, parece que, após o Estruturalismo, a Linguística salta de uma concepção de ciência até certo ponto ingênua para concepções mais elaboradas, cientes da íntima relação entre a fundamentação explanatória e a própria identificação do campo fenomenológico a ser considerado no terreno da descrição. E é justamente isso que faz com que diferentes abordagens, como o Gerativismo e a Sociolinguística, apesar de se debruçarem sobre a linguagem verbal, tratem de objetos de análise absolutamente distintos.

A adoção de uma perspectiva de fundo (sociológica, antropológica, psicanalítica ou cognitiva), no entanto, não garante explicações prontas. O normal, ao contrário, é que haja no interior de uma mesma corrente teórica, pontos de vista divergentes quanto aos mecanismos subjacentes à produção de fenômenos. Um bom exemplo são os modelos já propostos pelo Gerativismo. Partindo de um acordo generalizado de que a capacidade de formar frases decorre, na espécie humana, de um mecanismo inato, os gerativistas estão permanentemente buscando os princípios (cognitivos) subjacentes a essa capacidade. Esses princípios são o que se poderia chamar de base explanatória dos modelos, pensada de modo a garantir descrições apropriadas, capazes de separar, de modo preciso, construções gramaticais de agramaticais. Sabese, no entanto, que, dependendo da época, diferentes princípios foram postulados pelos gerativistas. Evidentemente, a sucessão de modelos distintos pretendeu aumentar a cobertura descritiva da teoria. Nenhum deles, no entanto, apesar das diferenças, abandonou o campo explicativo da cognição.

Este artigo propõe uma reflexão acerca de um problema explanatório que integra uma antiga discussão no campo da Pragmática Formal: a natureza das pressuposições (convencional ou conversacional?). O fato é que o estudo na Linguística (mais especificamente na Pragmática) da inferência chamada pressuposição permaneceu por três décadas assumindo que pressuposição é fenômeno de origem convencional, embora sujeito, em sua produção, a interferências de caráter conversacional. Essa suposição explanatória, que serviu de fundamento para sucessivos modelos descritivos, começou a ser questionada apenas depois da virada do milênio. Tendo em vista muitas características conversacionais das pressuposições (calculabilidade, cancelabilidade, não destacabilidade), muitos autores passaram a propor modelos teóricos em que alguns tipos de pressuposição ${ }^{1}$ são vistos como resultado de inferência decorrente de uma lógica da conversação.

A nova forma de encarar certos tipos de pressuposição, cujas primeiras aparições mais articuladas ocorreram em Simons $(20012,2002)$ e Abusch (2002), no entanto, só ganhou força a partir do momento em que começou a permitiu fundamentar a constituição de modelos teóricos capazes de descrever um problema descritivo clássico: o Problema da Projeção de Pressuposições. A partir do momento em que modelos baseados na nova explicação passaram a propor descrições capazes de predizer em que circunstâncias pressuposições idealmente ativadas por gatilhos pressuposicionais ${ }^{2}$ sobreviviam como

\footnotetext{
Mais especificamente, pressuposições associadas ao uso de gatilhos leves (soft triggers) passaram a ser vistas como fenômeno conversacional.

2 Apresenta-se,mais adiante, o conceito de gatilho pressuposicional. Por ora, é suficiente saber que são elementos da linguagem verbal responsáveis por disparar inferências pressuposicionais.
} 
pressuposições efetivas dos enunciados em que esses gatilhos se encontravam, a suposição de que pressuposição é fenômeno de natureza conversacional passou a disputar espaço no debate sobre o problema.

Há, atualmente, portanto, duas formas em disputa para explicar o surgimento de inferências pressuposicionais. De um lado, os convencionalistas - pertencentes às mais diversas correntes, tanto de índole pragmática quanto de índole semântica -, amparados em teorias com grande capacidade descritiva, permanecem defendendo que pressuposição é uma inferência que nasce de uma convenção, de uma marcação idiossincrática no léxico (em alguns casos, na sintaxe); de outro, os conversacionalistas começam a defender uma ideia distinta, a de que a inferência associada ao uso de certos gatilhos $^{3}$ em enunciados linguísticos decorre de princípios conversacionais de natureza geral.

Até bem pouco tempo, os contendores de um tal debate estariam limitados a apontar, nas abordagens concorrentes, falhas descritivas localizadas, que mais serviriam como estímulo para ajustes que para o abandono de perspectivas. Mais recentemente, contudo, o aperfeiçoamento das técnicas em Linguística Experimental acrescentou um novo elemento à disputa teórica. Como os modelos descritivos associados a cada uma das hipóteses explanatórias faz supor modos distintos de processamento de inferências pressuposicionais, percebeu-se que seria possível usar pesquisas que envolvessem a testagem de sujeitos em laboratório para verificar qual é a melhor hipótese, a de pressuposição como fenômeno convencional ou como fenômeno conversacional.

Diante desse novo quadro, as pesquisas voltadas a verificar a capacidade que crianças têm de realizar inferências pragmáticas também ganhou importância na esfera do debate teórico mais geral. $\mathrm{O}$ fato é que, se pressuposição for, como se passou a defender mais recentemente, fenômeno conversacional, espera-se que seu momento de aquisição seja o mesmo de outros fenômenos conversacionais considerados similares. Sendo assim, a investigação empírica sobre o momento em que ocorre a aquisição de pressuposições e outros fenômenos conversacionais, como implicaturas, pode ser elemento decisivo no debate acerca da natureza do fenômeno pressuposicional, constituindo, assim, um importante critério na escolha de modelos teóricos em disputa.

O objetivo desse artigo é mostrar como a pesquisa empírica com crianças sobre a compreensão de pressu-

\footnotetext{
Para ser mais preciso, é preciso dizer que as correntes mais recentes continuam a admitir o caráter convencional de uma série de gatilhos, mas inovam ao propor que muitas das pressuposições antes consideradas decorrência de marcação convencional são, de fato, resultado de cálculo conversacional.
}

posições e implicaturas de quantidade escalares pode oferecer elementos importantes para a decisão sobre qual das hipóteses em disputa acerca da natureza do fenômeno pressuposicional é mais adequada. Para tanto, divide-se em outras oito seções além desta introdução. A seção 2 apresenta o modo clássico de analisar pressuposição e implicatura de quantidade escalar. As seções 3 e 4 apresentam, respectivamente, o modo como abordagens mais recentes descrevem a geração de implicaturas de quantidade escalares e de pressuposições. A seção 5 identifica as predições das abordagens clássicas e das abordagens recentes para o processamento de implicaturas e pressuposições. Na seções 6 e 7, são relatados, respectivamente alguns estudos empíricos que corroboram a visão Clássica sobre implicaturas e pressuposições. Na seção 8 , é relatado um estudo que corrobora uma das visões recentes sobre implicaturas e pressuposições. A seção 9 apresenta os resultados de um estudo experimental com crianças que traz evidências para as hipóteses clássicas, mas que, com o acréscimo de certas suposições, ainda pode ser tomado como evidência para a hipótese mais recente. Por fim, a seção 10 apresenta considerações finais sobre a importância de estudos de aquisição de inferências pragmáticas como meio auxiliar para a escolha entre modelos teóricos em disputa.

\section{Implicaturas de quantidade escalares e pressuposições: visão tradicional}

A literatura pragmática, tradicionalmente, coloca implicaturas e pressuposições em campos fenomenológicos distintos. Implicaturas são inferências normalmente vistas como responsáveis pelo acréscimo de conteúdos não expressos literalmente, gerados a partir de uma lógica particular subjacente às trocas conversacionais. $\mathrm{O}$ segundo enunciado do diálogo abaixo produz uma implicatura de relação.

\section{(1) A: Vamos ao shopping fazer umas compras? \\ B: Tenho uma prova daqui a duas horas.}

Neste caso, percebe-se claramente que o falante B está recusando o convite. Essa recusa, no entanto, não é expressa de modo literal, mas inferida. Nos moldes das teorias griceanas, diz-se que a recusa em $\mathrm{B}$ decorre do respeito à máxima da relação, ou seja, o falante $\mathrm{A}$, ao procurar identificar que relação há entre o conteúdo de sua pergunta e o conteúdo da resposta que recebe, será capaz de derivar a inferência de que A não está em condições de sair.

Implicaturas de relação constituem os casos mais evidentes de transmissão de conteúdo produzido por mecanismos conversacionais, porque o conteúdo veicu- 
lado afasta-se de modo significativo do sentido literal das sentenças que as geraram. Além disso, implicaturas de relação são altamente dependentes de contexto. Em outro contexto, o proferimento da mesma sentença usada pelo falante B em (1) poderia ter um sentido particular totalmente diferente. Imagine, por exemplo, a situação em que a mesma sentença fosse usada como resposta ao oferecimento de uma xícara de café. Nesse caso, a mesma sentença poderia estar assumindo um sentido de aceitação.

Nem todas as implicaturas, no entanto, são tão dependentes de contexto como as de relevância, o que não impede que sejam resultado de inferência conversacional. O proferimento de uma sentença como (2a), por exemplo, costuma, de modo bastante regular, gerar a inferência em (2b).

(2a) Alguns esquilos saíram da toca.

(2b) Nem todos os esquilos saíram da toca.

Durante muito tempo, o conteúdo em (2b) foi considerado parte do sentido literal de (2a) - cf. Horn (1989). Hoje em dia, o ponto de vista predominante é aquele que considera (2b) uma inferência conversacional, mais especificamente, uma implicatura de quantidade escalar. Duas propriedades essenciais das implicaturas são suficientes para demonstrar que o conteúdo em (2b) é uma implicatura, e não parte do conteúdo literal: sua cancelabilidade e sua anulabilidade por contexto. A propriedade da cancelabilidade é ilustrada em (2c).

(2c) Alguns esquilos saíram da toca; na verdade, todos saíram.

Além de poder ser cancelada explicitamente pelo próprio enunciador, a implicatura em (2b) pode nem mesmo surgir em determinados contextos, como o apresentado em (2d).

(2d) Contexto: Pai e filho estão no zoológico. O pai sabe que o maior desejo do filho é conhecer os esquilos e que, num dia frio como aquele, é provável que eles estejam dentro da toca, escondidos. Chegando um pouco antes que o filho à frente da jaula dos esquilos, o pai percebe que há alguns esquilos fora da toca $\mathrm{e}$ profere (2a).

No contexto (2d), não é necessário inferir (2b) a partir do proferimento de (2a), pelo simples motivo de que não é possível assumir que o pai, que não é frequentador assíduo do zoológico, saiba quantos esquilos há, exatamente, para serem vistos. O que o pai quer dizer apenas é que já é possível enxergar esquilos, desejo maior do filho.
Implicaturas de quantidade escalar - extremamente regulares, mas, mesmo assim, resultado de inferência conversacional - decorrem, na perspectiva griceana, da ação de duas máximas, mais especificamente, da primeira submáxima da quantidade e da primeira submáxima da qualidade. Para que se possa compreender a ação dessas máximas no sentido de produzir implicaturas como $(2 b)$, é necessário, antes, reconhecer que os itens lexicais de um vocabulário podem ser agrupados em escalas de informatividade como (3).

(3) <todo, algum>

O que se vê em (3) é uma escala que apresenta dois quantificadores do português em uma sequência que obedece um critério de informatividade. $\mathrm{O}$ primeiro elemento da escala (todos) é mais informativo que o segundo elemento (alguns) porque o acarreta $^{4}$. Sendo assim, o enunciado (4) é mais informativo que o enunciado (2a), renumerado a seguir como (5).

(4) Todos os esquilos saíram da toca.

(5) Alguns esquilos saíram da toca.

Para respeitar a máxima da quantidade, portanto, o enunciador deveria ter proferido (4) em vez de (5). Ocorre que, quando se sabe que o enunciador tem condições de saber se (4) é verdade, considera-se que ele não tenha usado esse enunciado, em respeito à máxima da qualidade, por considerá-lo falso ${ }^{5}$. Entende-se, portanto, que deva acreditar em (6).

(6) Nem todos os esquilos saíram da toca.

Como se pode perceber, implicaturas de quantidade escalar geram inferências regulares, explicáveis a partir de fundamentos bastante razoáveis: interlocutores, em suas trocas conversacionais, procuram informar o máximo, respeitando, evidentemente, seus limites de conhecimento e, por isso, evitando transmitir informações com cuja verdade não podem se comprometer. Sendo assim, se o enunciador considerasse o conteúdo da sentença (4) verdadeira, em nome da transmissão da quantidade máxima de informação, a teria proferido; como não o fez, infere-se que esse falante esteja evitando transmitir a informação mais forte, provavelmente, por dela discordar.

\footnotetext{
4 O leitor interessado em saber por que um elemento acarretante é mais informativo que um acarretado encontra boa explicação no capítulo 4 de Oliveira e Basso (2014).

5 Há aqui uma simplificação que não pode ser evitada em virtude da exiguidade do espaço, mas que, no entanto, não afeta o argumento. O leitor interessado em uma descrição mais precisa pode encontrá-la em Soames (1991) e Sauerland (2004)
} 
Pressuposição, na perspectiva clássica de abordagem, diferentemente de implicatura, não remete à produção de conteúdo adicional, mas à manutenção de conteúdo em distintos contextos de enunciação. Um exemplo é o enunciado (7a), que pressupõe (7b).

(7a) Lia venceu a corrida.

(7b) Lia participou da corrida.

O conteúdo de (7b) é um acarretamento de (7a), mas é também uma pressuposição. Para identificar um conteúdo pressuposto há uma família de contextos linguísticos cf. Chierchia e Ginet (1990), como os apresentados a seguir.

(7c) Lia não venceu a corrida.

(7d) Lia venceu a corrida?

(7e) Talvez Lia tenha vencido a corrida.

(7f) Se Lia venceu a corrida, está feliz.

Todos tipos de sentenças acima (negativas, interrogativas, modais de possibilidade e condicionais) são capazes de eliminar acarretamentos, mas em nada afetam pressuposições. Pressuposição, então, não é propriamente um conteúdo adicional, mas um conteúdo normalmente imune a contextos canceladores de acarretamentos. Desde muito cedo, já na década de 70 , percebeu-se que uma série de elementos da linguagem verbal são responsáveis pela produção de pressuposições. Além de verbos como vencer, presente em (7), há outros tipos de verbos, como os factivos (lamentar, saber), aspectuais (parar, começar, continuar), bem como expressões iterativas (de novo, novamente, mais uma vez), além de muitos outros itens lexicais e construções. Todos esses elementos linguísticos foram batizados de gatilhos pressuposicionais em função de dispararem conteúdos muito estáveis, conteúdos pressupostos.

O termo pressuposição para referir o fenômeno de sentido associado ao uso dos gatilhos, usado já nos primeiros trabalhos sobre o assunto, reflete a sensação de que, pela regularidade observada, esses elementos são, na verdade, responsáveis pela veiculação de conteúdos considerados mutuamente compartilhados pelos interlocutores. Sendo assim, ao proferir alguma das sentenças em (7), o enunciador estaria veiculando como compartilhada a ideia de que Lia participou da corrida. Além disso, apesar da resistência desse tipo de inferência, logo se percebeu que se tratava de fenômeno pragmático em função da possibilidade de cancelamento, como se observa em (8).

(8) Lia não venceu a corrida porque não participou.
Em (8), a pressuposição não se projeta, ou seja, apesar de ser uma pressuposição tipicamente disparada pelo gatilho vencer, não se mantém como pressuposição efetiva do enunciado. Além de enunciados como (8), os estudos foram revelando muitos outros tipos em que as pressuposições idealmente ativadas por gatilhos não se projetam. O problema teórico de formular modelos descritivos capazes de identificar os mecanismos responsáveis pela manutenção ou o cancelamento de pressuposições ficou conhecido como o Problema da Projeção de Pressuposições.

Mesmo considerada fenômeno pragmático, sujeito, portanto, a injunções de ordem discursiva em sua produção, pressuposição tem, na perspectiva tradicional, uma natureza fundamentalmente distinta de implicaturas de quantidade. Enquanto pressuposições são consideradas resultado de uma marcação idiossincrática no léxico, fenômeno de natureza convencional, implicaturas são consideradas resultado de um processo conversacional, decorrente da consideração de heurísticas, mecanismos que permitem a identificação da intenção informativa dos falantes a partir da consideração de uma lógica particular às interações verbais. Classicamente, portanto, pressuposição é fenômeno bastante distinto de implicatura.

Em linhas gerais, a geração de implicaturas e pressuposições ocorreria esquematicamente como em (9) e (10), respectivamente.

(9) (a) Proferimento da sentença: "Alguns esquilos saíram da toca."

(b) Consideração das máximas conversacionais.

(c) Derivação da implicatura: "Nem todos os esquilos saíram da toca."

(10) (a) Proferimento da sentença: "Lia não venceu a corrida."

(b) Derivação da pressuposição: "Lia participou da corrida."

A comparação dos processos supostos em (9) e (10) para geração dos dois tipos de inferência revela que a produção de pressuposições, pela natureza convencional desse tipo de inferência, não conta com um estágio derivacional intermediário, como o que ocorre com implicaturas, que, dependem da consideração de máximas conversacionais. Essa compreensão acerca do modo como são produzidos esses dois tipos de inferência, portanto, faz supor que a geração de implicaturas é um processo cognitivamente mais custoso que a de pressuposições. Esse tipo de suposição tem implicações, como se verá mais adiante, para a abordagens experimentais. 


\section{As implicaturas de quantidade escalares em perspectivas mais recentes}

O mecanismo suposto para a geração de implicaturas de quantidade escalar, tal como foi apresentado na seção anterior, parte de uma compreensão de que a produção de determinados conteúdos percorre um caminho bem definido: primeiro o ouvinte decodifica o enunciado, determinando o seu sentido literal, para, em seguida, realizar considerações de ordem discursiva a fim de ampliar esse sentido literal em um processo de enriquecimento pragmático. Esse enriquecimento é fundamentalmente discursivo, já que leva em consideração uma lógica não padrão, que se constitui a partir da consideração de aspectos como relevância e quantidade de informação. O processo de geração de implicaturas de quantidade, na perspectiva tradicional, portanto, é presidido por mecanismos de natureza eminentemente conversacional.

O percurso griceano de descrição de geração de implicaturas, então, parte do pressuposto de que, em um primeiro momento, o significado literal da sentença proferida é formado de modo composicional. Nessa perspectiva, qualquer acréscimo de sentido pragmático decorrente da ação de máximas conversacionais ocorre sobre uma base já constituída, de sentido mais elementar, gerada em um módulo semântico. Nessa perspectiva, o sentido semântico de um enunciado seria o input para o cálculo do sentido pragmático, aquilo que Grice chamou de significado do falante.

Para Grice, e para os adeptos de sua visão, as implicaturas de um enunciado seriam acréscimos ao sentido literal da sentença proferida, computados somente após a geração desse sentido literal. Haveria, portanto, uma divisão de trabalho bastante regular entre os módulos semântico e pragmático, em que o primeiro serviria de input para ação do segundo. Segundo essa forma de explicar, tudo o que é produzido no módulo pragmático seria, nas palavras de Chierchia, Fox e Spector (2012), póscomposicional, ou seja, posterior à aplicação das regras de composição semânticas. Sendo assim, admitindo-se a sequencialidade das operações - em que as operações semânticas ocorrem apenas antes das pragmáticas -, é de se esperar que qualquer sigificado que seja produzido de modo composicional anteceda, de algum modo, qualquer consideração de caráter conversacional responsável por produzir sentidos acrescidos ao significado semântico.

Mais recentemente, no entanto, muito se tem discutido sobre a possibilidade de postular uma divisão tão precisa entre Semântica e Pragmática. Levinson (2000) chama atenção para uma série de casos em que aspectos pragmáticos parecem interferir no processamento semântico de enunciados, configurando o que o autor convencionou chamar de intrusão pragmática. Chierchia, Fox e Spector (2012) entendem que casos como (11) são exemplos de intrusão pragmática ${ }^{6}$.

(11) João está fortemente convencido de que se a maioria dos estudantes foi bem, ele vai se sentir feliz, e se todos eles foram bem, ele se sentirá mais feliz ainda.

O problema que (11) coloca é que, considerando o sentido global da frase, parece que a proposição expressa pela parte sublinhada só faz sentido se veicular a ideia de que nem todos os alunos foram bem. Essa é uma implicatura de quantidade escalar que, de acordo com a dinâmica de produção de sentido suposta pela lógica griceana, deveria ser produzida apenas após o proferimento do enunciado, sendo, portanto, pós-composicional. Não é isso, no entanto, que a intuição indica. Parece que, neste caso, a implicatura de que nem todos os alunos foram bem interage na fase composicional de formação de sentido, o que fica comprovado pelo contraste que se estabelece, pelos dois condicionais presentes no enunciado, entre o que João vai sentir em cada situação suposta (alguns, mas não todos, alunos irem bem, e todos alunos irem bem). Além disso, é preciso considerar que os dois condicionais estão encaixados em uma construção epistêmica, cujo sentido parece incluir o conteúdo implícito de uma das orações subordinadas.

Casos como esse-e muitos outros-levaram os autores a postular que, apesar de serem fenômenos pragmáticos, implicaturas de quantidade escalares realizam-se não em uma interface entre Semântica e Pragmática, mas sim entre Sintaxe e Pragmática. Na prática, os autores propõem que a geração de implicaturas de quantidade escalares resultam da ação de um operador sintático encoberto, o operador de exaustificação "O", que tem escopo sobre alternativas lexicalmente determinadas, as mesmas alternativas que formam as escalas de quantidade consideradas na seção anterior. Nessa perspectiva, sempre que uma sentença proferida contiver um item escalar, o operador de exaustificação age indicando, já no nível sintático, que as alternativas mais informativas devem ser rejeitadas. Sendo assim, uma sentença como (12a) deveria ser representada sintaticamente como $(12 b)^{7}$.

(12a) Alguns alunos foram bem.

(12b) $\mathrm{O}_{\mathrm{ALT}}$ (Alguns alunos foram bem $)^{8}$

\footnotetext{
6 O exemplo é uma tradução do original em Chierchia, Fox e Spector (2012).

7 Na representação proposta, ignoram-se detalhes sintáticos desnecessários a esta exposição.

8 A letra "o" maiúscula vem de "only" (somente), já que esse operador teria o efeito de determinar que, em uma escala como $<$ todos, alguns $>$, somente a proposição expressa pela sentença contendo membro mais fraco (alguns) pode ser considerada verdadeira.
} 
Como se pode perceber, a explicação dos autores para a geração de implicaturas de quantidade escalares distancia-se de modo significativo da visão tradicional, modelada pelo pensamento griceano. Agora, a geração de uma implicatura passa a ser operada já no nível sintático. O artigo dos autores é pródigo na apresentação de descrições bem sucedidas de casos de projeção e cancelamento de implicaturas a partir do mecanismo idealizado, bem como na identificação de problemas com a hipótese de que implicaturas sejam resultado de um processo fundamentalmente pós-composicional, como defendem as abordagens de índole griceana ${ }^{9}$.

\section{Pressuposições em perspectivas mais recentes}

Há inúmeros modelos de análise para lidar com o fenômeno pressuposicional. Historicamente, de acordo com uma longa tradição, pressuposição, embora suscetível a interferências de ordem conversacional, é fenômeno de natureza convencional. Durante muito tempo inferências pressuposicionais foram consideradas o resultado de marcação convencional no léxico. Dito de forma mais simples, no léxico das línguas, alguns itens seriam marcados como pressuposicionais, o que seria uma indicação, em situações de uso, de que determinados conteúdos veiculados pelo enunciado são parte do common ground, do conjunto de conteúdos mutuamente compartilhados pelos interlocutores. Para os autores responsáveis pela produção de trabalhos descritivos sobre pressuposição, ao longo de mais de três décadas, essa sempre foi a explicação para a origem de pressuposições. É bem verdade que nem sempre os teóricos envolvidos com o problema da projeção de pressuposições - o problema descritivo, que não é possível abordar aqui por razões de espaço - se contentaram com esse tipo de explicação, como se pode notar na passagem a seguir.

Em resumo, será assumido que pressuposições são disparadas por certos itens lexicais e construções sintáticas. A esse respeito, eu vou continuar uma longa tradição, porque os teoristas da pressuposição têm estado mais interessados apenas em dois problemas: projeção e desaparecimento de pressuposição. Ambos os problemas requerem, para a sua formulação, que pressuposições surjam de uma forma ou outra, e quase todo mundo tem-se considerado satisfeito de tomar isso como certo. De fato, tem-se duvidado de que o problema relacionado à origem das pressuposições mereça alguma atenção séria. $\operatorname{Gazdar}(1979$, p. 126), por exemplo, considera que seja uma 'tarefa teoricamente

\footnotetext{
9 O que não fica claro, no entanto, é o modo como essa nova perspectiva entende a relação entre sintaxe e pragmática.
}

trivial' especificar uma função que leve de palavras e tipos sintáticos a pressuposições. Eu mantenho que Gazdar está errado a respeito disso, e que a questão sobre a origem das pressuposições e a forma como são geradas merece investigação séria. E embora eu não tenha nada que se pareça com uma resposta completa para essa questão, o mínimo que eu posso fazer é tentar e mostrar que a questão é boa e dificil (GEURTS, 1999, p. 26 - grifo nosso).

A inquietação de Geurts começou a produzir reações mais engajadas alguns anos depois da publicação de seu livro, onde se encontra uma sofisticada aplicação da DRT - cf. Kamp e Reyle (1993) - para a descrição da projeção de pressuposições. Simons (2001) chama a atenção para muitas características conversacionais de pressuposições, todas já anteriormente identificadas, mas por ela reunidas em uma defesa mais contundente de uma alternativa explanatória de índole conversacional. $\mathrm{O}$ ponto de mutação na direção de propostas que aliassem uma explicação conversacional a soluções descritivas minimamente produtivas ocorre, no entanto, em Abusch (2002). Nesse artigo, a autora propõe que pressuposições sejam inferências decorrentes da consideração de certos tipos de escalas. A partir daí, não demorou muito para que alguns autores passassem a cogitar a possibilidade de que pressuposições fossem, na verdade, um tipo de implicatura de quantidade escalar.

Entre as propostas que passaram a circular, a mais articulada nesse sentido é a que se encontra na reflexão de Jacopo Romoli. Em uma série de trabalhos - cf. Romoli (2011, 2012, 2015) -, o autor passou a defender a ideia de que, em enunciados negativos e condicionais, pressuposições são implicaturas de quantidade escalares obrigatórias. Seu argumento, em linhas gerais, é o de que os gatilhos pressuposicionais, assim como os itens escalares responsáveis pela geração de implicatura de quantidade escalares, ativam escalas de quantidade informacional. Nessa perspectiva, na análise do gatilho vencer, por exemplo, a sentença (13a) torna acessível a escala (13b), e a sentença (14a) torna acessível a escala (14b).

(13a) Lia venceu a corrida.

(13b) < venceu, participou $>$

(14a) Lia não venceu a corrida.

(14b) < não participou, não venceu>

Como se pode observar, aqui a lógica é a mesma que fundamenta a constituição das escalas envolvidas em implicaturas: o elemento à esquerda acarreta o elemento à direita, sendo, por isso, mais informativo. Vale lembrar que tanto o proferimento de (13a) quanto o de (14a) produzem a inferência (15). 
(15) Lia participou da corrida.

Em relação a (13a), essa inferência não oferece problemas descritivos, já que é um acarretamento semântico. A solução de Romoli é interessante para explicar porque (15) é uma consequência de (14a), uma vez que não se configura como uma conclusão necessária, como bem revela (16).

(16) Lia não venceu a corrida porque não participou.

O que Romoli propõe como solução é que o proferimento de (14a) torna acessível a escala (14b), e que, a partir da ação do operador sintático de esxaustificação (referido na seção 3 deste artigo), produza-se a rejeição do elemento mais forte dessa escala (não participou), gerando a inferência esperada (participou). Percebe-se, então, que, de acordo com essa maneira de descrever a projeção da inferência, muitos dos casos usualmente considerados pressuposições são, na verdade, implicaturas escalares. Mais especificamente, Romoli propõe que inferências geradas por gatilhos leves ${ }^{10}$ sejam implicaturas escalares obrigatórias.

\section{Predições das abordagens clássicas e das abordagens recentes para o processamento de implicaturas e pressuposições}

A seções 2, 3 e 4 deste artigo expuseram o modo como implicaturas de quantidade escalares e pressuposições são vistas pelo que se poderia considerar a tradição pragmática e por uma tendência mais recente, na qual se desloca a geração de inferências conversacionais da interface Semântica-Pragmática para a interface SintaxePragmática. Para além das discussões de caráter mais geral que um tal deslocamento suscita, as duas formas de explicar os fenômenos são passíveis de testagem empírica. Isso porque as hipóteses a elas associadas, apresentadas a seguir, permitem supor processamento distintos para cada um dos tipos de inferência ${ }^{11}$.

\footnotetext{
${ }^{10}$ Não há espaço aqui para esclarecer a distinção entre gatilhos leves e pesados. Para os objetivos este trabalho, basta saber que gatilhos leves são aqueles que produzem inferências com comportamentos particulares, sendo o principal a possibilidade de cancelamento.

11 Para efeito de discussão, vamos considerar as hipóteses A e B como elementos do conjunto "Visão Clássica", e a hipótese C como "Visão de Romoli". Cada uma dessas visões prevê comportamentos particulares para a interpretação de enunciados com os tradicionais elementos escalares e os tradicionais gatilhos pressuposicionais, tanto no que diz respeito à aceitação de enunciados cujas inferências não possam ser aceitas, quanto no que diz respeito ao tempo de processamento dessas inferências.
}

A - Implicatura Escalar - Visão Clássica

(predominante até o ano 2000)

Implicatura escalar é resultado de cálculo conversacional a partir de conteúdo entregue pelo módulo semântico.

B - Pressuposição - Visão Clássica

(predominante até o ano 2000)

Pressuposição linguística é resultado de marcação

convencional, registrada no léxico, destinada a apresentar conteúdo como compartilhado entre os interlocutores.

\section{C - Implicatura Escalar e Pressuposição - Visão de Romoli}

Pressuposição disparada por gatilhos leves é um tipo de implicatura escalar (implicatura escalar obrigatória). Nos dois casos, a inferência é pragmática, mas é integrada composicionalmente ao sentido da sentença a partir da ação de um operador sintático (operador de exaustificação).

De acordo a Visão Clássica, como implicatura de quantidade escalar constitui fenômeno conversacional e pressuposição, fenômeno convencional, o desacordo entre o conteúdo de uma implicatura e o que o intérprete considera que sejam os fatos deve ser mais facilmente admitido que o desacordo entre o conteúdo de uma pressuposição e os fatos. De acordo com a Visão de Romoli, no entanto, esse tipo de desacordo deve ter o mesmo tipo de aceitação nos dois casos, já que, para ele, nos dois há implicatura de quantidade escalar. Sendo assim, para a visão tradicional, o intérprete deve apresentar maior resistência em concordar com o enunciado (18b) na situação (18a) do que a esperada diante do enunciado (17b) na situação (17a). Já para a Visão de Romoli, a aceitação de enunciados como (17b) e (18b) em situações como (17a) e (18a) deve ser similar.

(17a) Situação: O intérprete sabe que todos os alunos foram à aula.

(17b) Alguns alunos foram à aula.

(18a) Situação: O intérprete sabe que Lia não participou da corrida.

(18b) Lia não ganhou a corrida.

Também no que diz respeito ao tempo de processamento, as duas visões fazem predições distintas. Segundo a Visão Clássica, como implicatura envolve considerações de ordem conversacional, seu processamento deve levar mais tempo que o de pressuposições, que, de acordo com a mesma visão, envolve apenas o reconhecimento de uma convenção, não 
implicando, portanto, qualquer cálculo conversacional. Já a visão de Romoli, por considerar pressuposição um tipo de implicatura escalar, prevê um tempo similar de processamento para os dois fenômenos.

Há, portanto, independentemente da discussão de fundo mais geral quanto à plausibilidade de um modelo que desloca a análise da geração de fenômenos conversacionais da interface Semântica-Pragmática para a interface Sintaxe-Pragmática, a possibilidade de corroborar alguma dessas hipóteses com base na realização de experimentos que verifiquem aceitação e tempo de processamento de enunciados com itens escalares e gatilhos pressuposicionais. Estudos experimentais foram realizados, mas, ao contrário do que se poderia esperar, acabaram, dependendo do método usado, corroborando hipóteses contraditórias. Nas próximas seções, alguns desses estudos, com seus resultados, são apresentados.

\section{Estudo que corrobora a visão clássica sobre implicaturas: paradigma de julgamento de valor-de-verdade}

O artigo clássico sobre interpretação e processamento de implicaturas escalares é Bott e Noveck (2004). Antes de apresentar os resultados desse estudo, é importante ter clareza sobre seu objetivo. O estudo foi realizado no momento em que se apresentavam duas visões antagônicas sobre a produção de implicaturas. De um lado, a Teoria da Relevância, de Sperber e Wilson, defendia a ideia de que todas as implicaturas deveriam ser descritas nos moldes de um só princípio, responsável pela produção de inferências na base de um processo de busca de conteúdos na memória. De acordo com essa perspectiva, enriquecimentos pragmáticos só aconteceriam se justificados pela busca de relevância, de modo que o output de um processo semântico poderia permanecer inalterado após a ação do módulo pragmático se nenhum enriquecimento fosse necessário para satisfazer certas expectativas de relevância.

De outro lado estava a uma teoria de inferências default, defendida em Levinson (2000). De acordo com Levinson, diferentemente de implicaturas de relação, implicaturas generalizadas ocorreriam - em respeito a uma série de injunções de ordem pragmática - de um modo automático, sem depender, portanto, de considerações de aspectos contextuais para sua produção. Entre esses fenômenos estariam as implicaturas de quantidade escalar, cuja regularidade chegou a fazer com que alguns supusessem ser fenômeno semântico ${ }^{12}$.

\footnotetext{
12 O leitor interessado em acompanhar a série de problemas associados à suposição de que implicatura escalar sejam fenômeno de natureza semântica encontra um histórico completo em Horn (1989).
}

Essas duas formas de encarar a ação do módulo pragmático permitem realizar predições bastante precisas acerca do modo de interpretação e do tempo de processamento de implicaturas escalares. O objetivo de Bott e Noveck (2004) foi o de, a partir de testes experimentais, oferecer suporte a uma dessas duas visões em competição. Para tanto, realizaram quatro experimentos, dos quais apenas o primeiro é apresentado detalhadamente aqui, em função de limitações de espaço.

No primeiro experimento, os pesquisadores apresentaram aos sujeitos da pesquisa seis tipos de sentença, exemplificados a seguir.

(19a) Alguns elefantes são mamíferos. ?

(19b) Alguns mamíferos são elefantes. V

(19c) Alguns elefantes são insetos. F

(19d) Todos os elefantes são mamíferos. V

(19e) Todos os mamíferos são elefantes. F

(19f) Todos os elefantes são insetos. F

Como se pode ver pelos valores-de-verdade ao lado de cada enunciado, todos, com exceção de (19a), são inequivocamente verdadeiros ou falsos. $\mathrm{O}$ único que pode gerar alguma dúvida é (19a), conforme se considere, ou não, o conteúdo da implicatura escalar. Sendo assim, (19a) seria julgado verdadeiro por quem se ativesse apenas ao seu significado literal e falso por quem considerasse adicionalmente a implicatura de que nem todos os elefantes são mamíferos.

No experimento 1, no entanto, os pesquisadores não deram margem a uma interpretação livre dos participantes. Ao contrário, dividiram-nos em dois grupos. Um grupo foi treinado a realizar a interpretação lógica do enunciado (19a), sendo estimulado a considerá-lo, portanto, verdadeiro. Outro grupo foi treinado a realizar a interpretação pragmática de (19a), sendo estimulado a considerá-lo falso. Sendo assim, se um sujeito do grupo 1 considerasse (19a) verdadeiro, sua opção seria computada como um uma resposta certa; se considerasse (19a) falso, sua opção seria computada como uma resposta errada. Para um integrante do segundo grupo, seria o contrário. Além disso, mediram-se os tempos de resposta para cada sentença avaliada pelos sujeitos dos dois grupos. O Gráfico 1, adinte, apresenta os índices médios de acerto para cada enunciado nos dois grupos: lógico e pragmático.

Considerando todos os enunciados medidos, o único enunciado que apresentou diferença de acertos estatisticamente relevante foi o enunciado-alvo, o enunciado 1. Em todos os demais enunciados, os enunciados-controle, embora tenha havido alguma 
diferença no índice de acertos, nenhuma se mostrou estatisticamente significativa. Como se pode ver, no enunciado-alvo, os sujeitos erraram muito mais (apenas $65 \%$ de acerto) a condição inferência pragmática, o que sugere maior dificuldade de processamento nessa condição, contrariamente ao que prevê a abordagem de Levinson, que considera implicatura escalar uma inferência default, devendo ser fácil de processar e, portanto, de julgar.

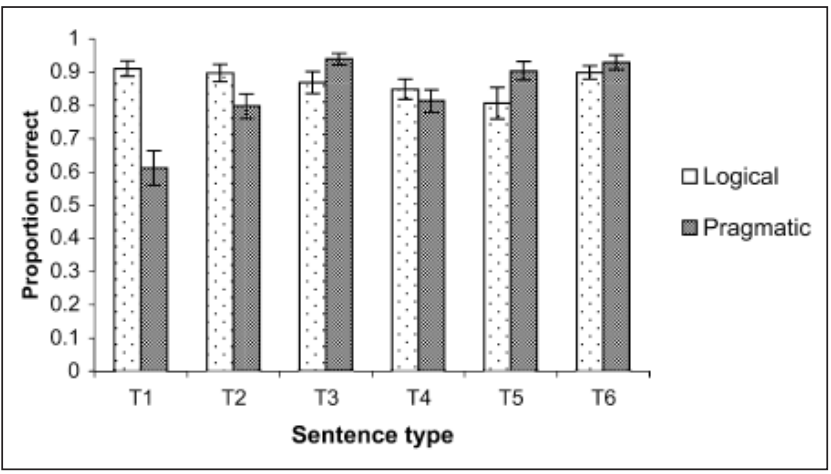

Gráfico 1. Índices médios de acerto registrados no experimento 1 em Bott e Noveck (2004)

A diferença verificada nos tempos de processamento das duas condições (lógica e pragmática) também favoreceram a visão defendida pela Teoria da Relevância, conforme se vê no Gráfico 2.

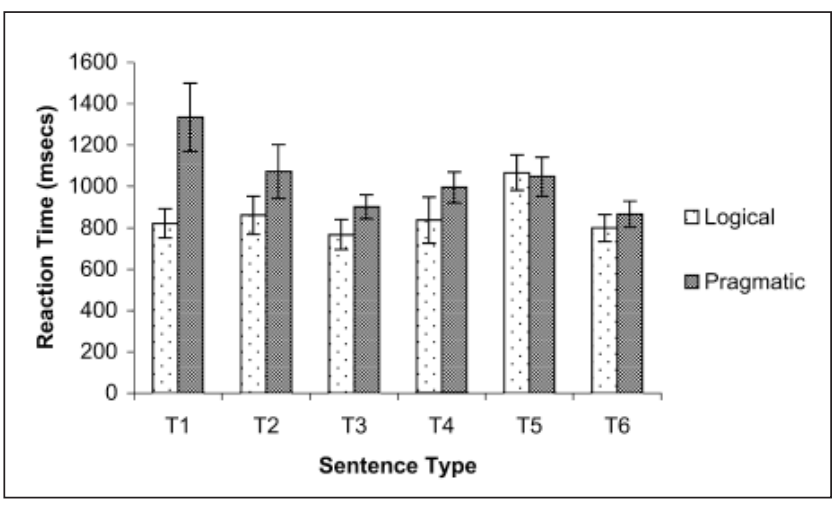

Gráfico 2. Tempos médios de resposta registrados no experimento 1 em Bott e Noveck (2004)

Aqui, mais uma vez, não houve diferença estatisticamente relevante entre os resultados das sentençascontrole nas duas condições. Já na sentença-alvo (T1) observa-se um processamento significativamente mais rápido na condição lógica, revelando que a produção da inferência pragmática exige maior tempo de processamento, o que reforça a hipótese de que impli- caturas escalares não são inferências default, como entende Levinson, mas, ao contrário, são realizadas como resultado de um processo pragmático, conversacional.

Num segundo experimento, os pesquisadores mudaram apenas a forma das frases e as possibilidades de julgamento. O objetivo foi verificar se os resultados do primeiro experimento não seriam consequência de algum enviesamento decorrente do fato de que os sujeitos da pesquisa deveriam, dependendo do grupo em estivessem inseridos (o grupo da interpretação lógica ou o grupo da interpretação pragmática), responder de modo diferente: uns com verdadeiro, outros com falso. A suspeita seria a de que o julgamento de sentenças falsas poderia implicar maior tempo de processamento, o que poderia ser a razão de os sujeitos da condição pragmática (que deveriam responder com falso) levarem mais tempo para dar suas respostas aos estímulos. Para evitar isso, os sujeitos agora deveriam dizer se concordavam ou não com os seguintes enunciados ${ }^{13}$.

(20a) Maria disse que a seguinte sentença é verdadeira: Alguns elefantes são mamíferos.

(20b) Maria disse que a seguinte sentença é falsa: Alguns elefantes são mamíferos.

Agora, os sujeitos da condição lógica eram apresentados a (20a) e os da condição pragmática, a (20b). Dessa forma, os dois grupos seriam avaliados com base em uma mesma resposta ("concordo"), o que evitaria qualquer enviesamento em função da diferença entre as respostas verdadeiro e falso. Essa alteração no formato dos enunciados, no entanto, não provocou alteração significativa nos resultados. Os índices de acerto permaneceram similares aos do experimento 1 , bem como os tempo de processamento.

Num terceiro experimento, os pesquisadores não forneceram instrução sobre o modo como julgar os enunciados, deixando os sujeitos livres para considerarem verdadeira ou falsa cada sentença apresentada. Depois de feitos os testes, os sujeitos foram divididos em dois grupos: dos respondedores lógicos e o dos respondedores pragmáticos. Nesse caso, caberia apenas verificar os tempos de processamento. Mais uma vez, os respondedores lógicos demoraram significativamente menos tempo que os respondedores pragmáticos.

Por fim, os pesquisadores aplicaram um teste similar aos dos experimentos 1 e 3 (em que os sujeitos precisaram atribuir um valor-de-verdade aos enunciados) em dois grupos. A diferença agora era que havia um tempo limite para as respostas. Um grupo teve pouco tempo para responder, enquanto o outro teve um

\footnotetext{
13 Apresenta-se aqui apenas o enunciado-alvo.
} 
tempo significativamente maior. A expectativa, que se confirmou, era a de que o grupo com menos tempo teria um índice de respostas pragmáticas menor que o grupo com mais tempo. A confirmação dessa expectativa reforçou ainda mais a suposição de que implicaturas escalares são inferências não automáticas (contrariamente ao que defende Levinson); são inferências realizadas a partir de um input semântico com base em injunções de natureza conversacional, que levam algum tempo para serem realizadas.

\section{Estudo que corrobora a visão clássica sobre pressuposições: paradigma de julgamento de valor-de-verdade}

Assim como Bott e Noveck realizaram experimentos com a finalidade de avaliar a plausibilidade de duas teorias relativas ao modo como são produzidas implicaturas, Chemla e Bott (2013), seguindo os mesmos moldes (utilizando o mesmo paradigma de julgamento de valorde-verdade), realizaram experimentos para avaliar duas hipóteses distintas relativas à produção de pressuposições. Neste caso, no entanto, a comparação ocorreu entre abordagens semânticas e abordagens pragmáticas.

Em linhas gerais, abordagens semânticas sobre pressuposições se distinguem das pragmáticas relativamente ao modo como supõem a ação do operador de negação. Para as abordagens semânticas, a negação opera apenas sobre conteúdo asseverado, deixando intacto o conteúdo pressuposto. Já as abordagens pragmáticas, em linhas gerais, caracterizam-se por supor que a negação atua indiscriminadamente sobre os dois tipos de conteúdos, descrevendo a especificação de escopo sobre a porção asseverada como uma operação posterior, realizada no estágio pragmático de processamento. Sendo assim, um enunciado como (21) é representado como (22a) por teorias semânticas da pressuposição e como (22b) por teorias pragmáticas.

(21) Zoólogos não perceberam que elefantes são répteis.

(22a) Elefantes são répteis \& - (Zoólogos perceberam que elefantes são répteis)

(22b) $\ulcorner$ (Elefantes são répteis \& Zoólogos perceberam que elefantes são répteis)

De acordo com a perspectiva semântica, portanto, a pressuposição já é um resultado da interpretação semântica. Nessa perspectiva, uma sentença como (23), por ser aceitável, exigiria uma reinterpretação, em que o conteúdo pressuposto, já projetado no nível semântico, acaba por deslocar-se para o interior da representação parentética.
(23) Zoólogos não perceberam que elefantes são répteis, porque os elefantes não são répteis.

Para o defensor de uma abordagem semântica de pressuposições, a formalização em (22b) é resultado de um processo pragmático posterior de reinterpretação, que pode revelar-se necessário em enunciados como (21) (a fim de evitar a produção de conteúdos contraditórios). A esse processo de deslocamento do conteúdo pressuposto na representação formal chamam de acomodação local. Na perspectiva semântica, portanto, a interpretação mais elementar de um enunciado como (21) é aquela em (22a), em que a porção de conteúdo pressuposto é sentida como global. Chemla e Bott chamam essas abordagens de modelos primeiro global (global-first models).

Já as abordagens pragmáticas são caracterizadas pelos autores como modelos primeiro local (local-first models). Para essa abordagens, a representação semântica de (21) é (22b), em que a negação tem escopo amplo sobre todos os conteúdos veiculados pelo enunciado. De acordo com essas abordagens, é apenas no estágio pragmático de processamento que ocorre a especificação de escopo normalmente verificada. Para essas abordagens, portanto, enunciados como (23) impedem o processo posterior de especificação de escopo, já que não oferecem as condições pragmáticas para esse tipo de operação (porque a especificação de escopo, nesses casos, representaria uma infração à máxima da qualidade).

Como, no campo das descrições, os dois tipos de abordagem alcançam um considerável sucesso descritivo, é possível, a fim de acrescentar elementos para a decisão sobre o melhor modelo, realizar testes de processamento. Neste caso, as duas hipóteses permitem prever processamentos bastante distintos para enunciados com gatilhos pressuposicionais. Em relação à aceitação, teorias semânticas preveem que, de um modo geral, interlocutores considerem falsos enunciados como (21), já que a pressuposição, que é semântica, conflita com conhecimento de mundo bastante estável. Teorias pragmáticas, ao contrário, por postularem uma representação semântica em que a negação tem escopo amplo, preveem uma maior aceitação, já que a negação, no nível semântico, admite a rejeição do conteúdo pressuposto.

Em relação aos tempos de processamento, os dois modelos também fazem previsões distintas ${ }^{14}$. Teorias semânticas de pressuposições predizem uma rejeição rápida de (21), já que a representação semântica entra em conflito direto com conhecimento de mundo bem estabelecido. Essas mesmas teorias admitem,

\footnotetext{
14 Aqui, evidentemente, é preciso considerar que o processamento de enunciados ocorre sequencialmente, com as operações do nível semântico antecedendo as do nível pragmáticos.
} 
evidentemente, que o enunciado seja aceito como verdadeiro, mas, nesse caso, preveem um maior tempo de processamento, já que a acomodação local (estimulada pelo conflito entre conteúdo pressuposto e conhecimento de mundo) é uma operação pragmática subsequente.

As abordagens pragmáticas, por sua vez, fazem predições opostas às das abordagens semânticas. Como, nessa perspectiva, na representação semântica a negação tem escopo amplo, espera-se que intérpretes dispostos a aceitar como verdadeiro o enunciado (21) o façam com razoável rapidez, dado que estarão, neste caso, aderindo à interpretação relativa à representação mais elementar. Já os intérpretes que rejeitem (21) deveriam demorar mais tempo, tendo em vista que a especificação de escopo da negação, nessa abordagem, ocorre apenas no nível pragmático de intepretação. De modo resumido, as predição dos dois tipos de abordagem são apresentadas em (24) e (25).
(24) Abordagens semânticas
Rejeição < Aceitação
(25) Abordagens pragmáticas
Aceitação $<$ Rejeição

Com a finalidade de oferecer suporte a um dos modelos apresentados, Chemla e Bott realizaram dois experimentos inspirados naqueles encontrados em Bott e Noveck (2004). O primeiro experimento consistiu na apresentação dos cinco tipos de enunciado em (26) aos sujeitos da pesquisa, dos quais (26a) consiste no enunciado-alvo e os demais constituem controles.

(26a) Zoólogos não perceberam que elefantes são répteis. ?

(26b) Zoólogos não perceberam que elefantes são mamíferos. $\mathrm{F}$

(26c) Geógrafos não perceberam que elefantes são mamíferos. $\mathrm{V}$

(26d) Zoólogos foram informados que elefantes são mamíferos. $\mathrm{V}$

(26e) Zoólogos foram informados que elefantes são répteis. $\mathrm{F}$

Para que esses enunciados fizessem sentido e pudessem ser avaliados de modo regular pelos sujeitos da pesquisa, o experimento inicia-se com a sua contextualização a partir de uma história. Nessa história, informa-se aos sujeitos que houve uma invasão alienígena na Terra. Os alienígenas que aqui chegaram foram divididos por seus líderes em dois grupos incumbidos de estudar as características do planeta: um grupo de geógrafos, responsável pelo estudo da geografia da Terra, e um grupo de zoólogos, responsável pelo estudo dos animais. Ainda segundo essa história, os geógrafos nada aprenderam sobre nossos animais e os zoólogos nada aprenderam sobre nossa geografia.

Apenas esse contexto inicial foi suficiente para permitir que se considerassem inequivocamente falsos os enunciados (26b) e (26e) e inequivocamente verdadeiros os enunciados (26c) e (26d). O enunciado-alvo, (26a), no entanto, poderia ser considerado verdadeiro ou falso, conforme se fizesse uma interpretação em que a negação tivesse escopo amplo ou restrito, respectivamente. A intenção era ver qual seria o tempo de processamento de cada uma das interpretações. Se os sujeitos que rejeitassem (26a), considerando-a falsa, realizassem seu processamento em tempo menor que os sujeitos que a aceitassem, o estudo estaria apontando para a correção da hipótese semântica, segundo a qual a pressuposição se projeta para fora do escopo da negação já no estágio semântico. Se, ao contrário, os sujeitos que aceitassem (26a), considerando-a verdadeira, realizassem seu processamento em tempo menor que os sujeitos que a rejeitassem, o estudo estaria apontando para a correção da hipótese pragmática, segundo a qual a pressuposição, no estágio semântico, está sob o escopo da negação.

Para tabular seus resultados, os pesquisadores dividiram os sujeitos que participaram do experimento em dois grupos: o grupo dos que aceitaram e o dos que rejeitaram enunciados como (26a). Para cada um desses grupos, fizeram a média dos tempos de resposta ${ }^{15}$, chegando ao resultado apresentado nas colunas do Gráfico 3 abaixo ${ }^{16}$.

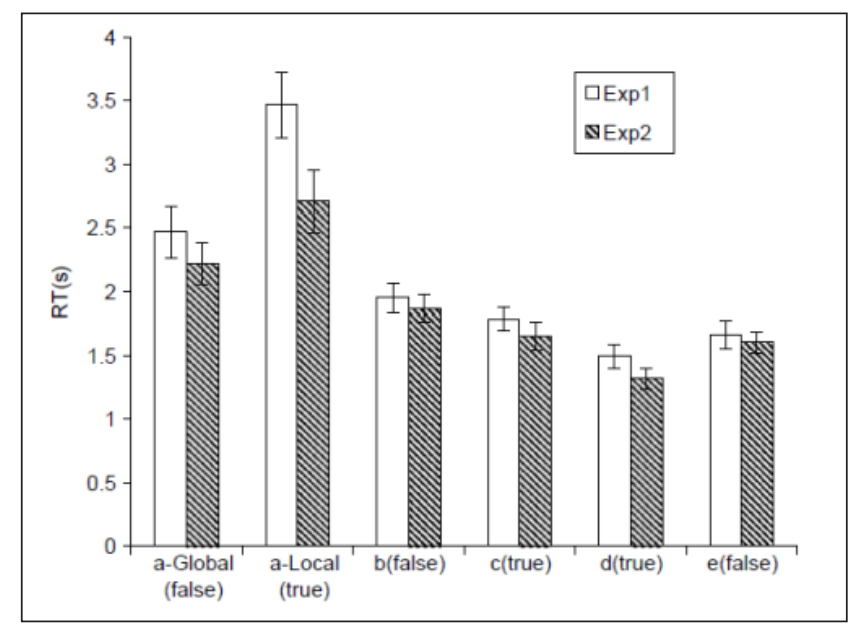

Gráfico 3. Tempos médios de resposta registrados no experimento 1 em Chemla e Bott (2013)

\footnotetext{
$\overline{15 \text { Como os enunciados }} \mathrm{b}, \mathrm{c}, \mathrm{d}$, e foram interpretados do mesmo modo por todos os sujeitos, as colunas do gráfico relativas a esses enunciados registram a média de todos os participantes,

${ }^{16}$ As colunas cinzas registram o resultado do segundo experimento realizado pelos autores, mencionado a seguir.
} 
Como se pode ver, o tempo médio de processamento dos sujeitos que consideraram a pressuposição fora do escopo da negação (leitura global da pressuposição) é consideravelmente menor (a diferença foi estatisticamente relevante) que o tempo médio de processamento dos sujeitos que consideraram a pressuposição dentro do escopo da negação (leitura local da pressuposição). Esse resultado oferece apoio às teorias semânticas de pressuposições, que, pelo modo como descrevem a projeção de pressuposições, preveem que a rejeição de enunciados como (26a) deve ser mais rápida que sua aceitação.

Os resultados apresentados nesta seção e na anterior corroboram, de modo muito claro, visões bastante tradicionais sobre implicaturas e pressuposições. De acordo com essas visões, implicatura é fenômeno conversacional, sendo, portanto, resultado de cálculo pragmático. $\mathrm{O}$ estudo de Bott e Noveck apresentado na seção anterior, ao registrar tempo de resposta mais lentos entre os sujeitos que demonstraram realizar implicaturas, indica justamente esse caráter conversacional do fenômeno. As mesmas visões tradicionais consideram pressuposição, diferentemente de implicaturas, fenômeno de natureza convencional (seja uma convenção pragmática, seja uma convenção semântica). O resultado de Chemla e Bott, apresentado nesta seção, aponta para essa compreensão ao registrarem tempos menores de processamento entre os sujeitos que processam os enunciados projetando a pressuposição.

\section{Estudo que corrobora a visão de Romoli sobre implicaturas e pressuposições: paradigma de aceitação/rejeição}

Nas duas seções anteriores, vimos que os experimentos realizados com pressuposições e implicaturas produziram resultados bastante distintos em relação ao tempo de processamento nas duas condições cruciais para a análise: produção e não produção da inferência. Para implicaturas, Bott e Noveck (2004) entregou os seguintes resultados.

(27) Não produção da implicatura < Produção da implicatura

Ou seja, os sujeitos da pesquisa treinados para fazer apenas a leitura lógica de (28) - compatível com o fato de que todos os elefantes são mamíferos levaram menos tempo para considerá-la verdadeira que os sujeitos da pesquisa treinados para fazer apenas a leitura pragmática de (28) - incompatível com o fato de que todos os elefantes são mamíferos - levaram para considerá-la falsa.
(28)

Alguns elefantes são mamíferos.

No caso das pressuposições, Chemla e Bott (2013) chegaram a resultados opostos. Seu estudo mostrou que uma sentença como (29) é interpretada em menos tempo na situação em que a inferência pressuposicional é mantida - caso em que a sentença é julgada falsa que na situação em que a inferência pressuposicional é rejeitada - caso em que a sentença é julgada verdadeira -, entregando o resultado apresentado em (30).

Zoólogos não perceberam que elefantes são répteis.

Produção da pressuposição < Não produção da pressuposição

Para que a comparação fique mais fácil, os dois resultados são apresentados em (31).

(31) Não produção da implicatura < Produção da implicatura

Não produção da pressuposição > Produção da pressuposição

Como se pode ver, os padrões são opostos. Enquanto, de acordo com esses estudos, enunciados com implicaturas tem um tempo de processamento maior que os mesmos enunciados sem implicaturas; enunciados com pressuposições têm um tempo de processamento bem mais rápido que os mesmos enunciados sem a pressuposição.

Os dois resultados estão de acordo com a visão clássica sobre implicaturas e pressuposições e contrariam a visão de Romoli, segundo a qual implicaturas escalares e pressuposições são, na verdade, um mesmo fenômeno (cf. seção 4 deste artigo). De um lado, esses resultados corroboram a ideia (clássica) de que implicatura é fenômeno conversacional, já que a medição do tempo de processamento revelou que sua produção toma algum tempo a mais (em relação a sua não produção). De outro, reforçam a ideia (também clássica) de que pressuposição é fenômeno convencional, já que a medição do tempo de processamento revelou que sua produção toma algum tempo a menos (em relação a sua não produção).

Empenhado em comprovar sua hipótese, Jacopo Romoli, em Romoli e Schwarz (2015) e Bill, Romoli e Schwarz (manuscrito ainda não publicado) compara os tempos de processamento de implicaturas escalares e pressuposições usando um paradigma investigativo distinto. Em vez de verificar o valor-de-verdade atribuído a sentenças pelos sujeitos investigados, os estudos adotam o paradigma da caixa encoberta. Nesse paradigma, o sujeito é apresentado incialmente a um enunciado linguístico. Após a leitura desse enunciado, o sujeito é apresentado a duas imagens. Uma delas é uma figura que 
pode justificar (em alguma medida) ou não a aceitação do enunciado previamente lido. A outra é uma caixa preta, sob a qual, diz-se ao sujeito, estará sempre a imagem adequada ao enunciado sempre que ele não aceitar a imagem explícita. $\mathrm{O}$ estudo apresentado nesta seção é o que é reportado no manuscrito, ainda não publicado, de Bill, Romoli e Schwarz, em que os autores avaliam os tempos de processamento relacionados a interpretações de enunciados com implicaturas escalares diretas (em enunciados afirmativos), implicaturas escalares indiretas (em enunciados negativos) e pressuposições em enunciados negativos ${ }^{17}$.

O primeiro experimento realizado pelos autores teve o objetivo de comparar o processamento de implicaturas escalares diretas e indiretas, como as que aparecem em (32b) e (33b) associadas a enunciados como (32a) e (33a).

(32a) João foi algumas vezes ao cinema.

(32b) João não foi algumas vezes ao cinema.

(33a) João não foi sempre ao cinema.

(33b) João foi algumas vezes ao cinema.

Para fazer a comparação, os experimentos apresentavam um desses dois enunciados seguidos de uma das três possíveis combinações de imagens a seguir.
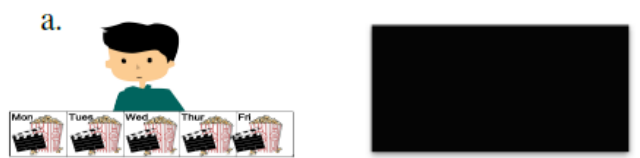

(34)

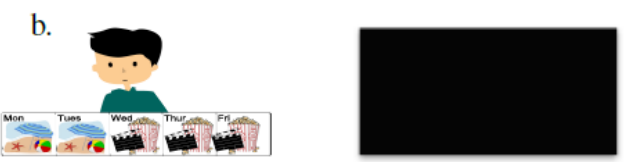

(34)

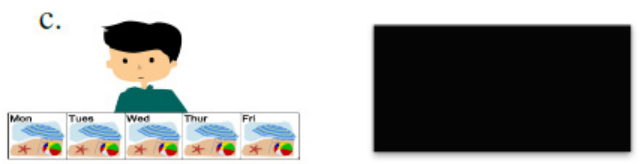

Na situação em que lê (32a), o sujeito que se depara com (34a) encontra uma figura condizente apenas com a leitura literal do enunciado. Nesse caso, a escolha da figura indica disposição para considerar verdadeiro o enunciado, apesar da violação de sua implicatura (32b). Já a escolha da caixa preta indica a não aceitação do enunciado justamente por representar, na situação descrita, uma violação da implicatura (32b). Aqui, os sujeitos que escolheram a figura aberta foram considerados como

\footnotetext{
$17 \mathrm{O}$ mesmo artigo compara ainda os tempos de processamento de pressuposições e acarretamentos em enunciados afirmativos, resultados que não serão aqui abordados.
}

tendo feito uma leitura literal, enquanto os que escolheram a caixa encoberta foram considerados como tendo feito uma leitura inferencial.

$\mathrm{Na}$ situação em que lê (32a) ou (33a), o sujeito que se depara com (34b) encontra uma figura condizente com a leitura inferencial do enunciado. Esse foi um caso de escolha quase categórica da figura aberta. Aqui, embora a figura aberta pudesse ser escolhida por falantes que toleram a leitura não inferencial, os sujeitos que a escolheram foram considerados como tendo feito uma leitura inferencial.

$\mathrm{Na}$ situação em que lê (32a), o sujeito que se depara com (34c) encontra uma figura aberta que torna o enunciado literalmente falso. Como era de se esperar, a escolha da figura aberta foi próxima de zero. Aqui, os sujeitos que escolheram a figura encoberta (quase a totalidade) foram considerados como tendo feito uma leitura literal.

$\mathrm{Na}$ situação em que lê (33a), o sujeito que se depara com (34a) encontra uma figura aberta que torna o enunciado literalmente falso. Como era de se esperar, a escolha da figura aberta foi próxima de zero. Aqui, os sujeitos que escolheram a figura encoberta (quase a totalidade) foram considerados como tendo feito uma leitura literal.

Na situação em que lê (33a), o sujeito que se depara com (34c) encontra uma figura condizente apenas com a leitura literal do enunciado. Nesse caso, a escolha da figura indica disposição para considerar verdadeiro o enunciado, apesar da violação de sua implicatura (33b). Já a escolha da caixa preta indica a não aceitação do enunciado justamente por representar, na situação descrita, uma violação da implicatura (33b). Aqui, os sujeitos que escolheram a figura aberta foram considerados como tendo feito uma leitura literal, enquanto os que escolheram a caixa encoberta foram considerados como tendo feito uma leitura inferencial.

Como não há espaço aqui para reproduzir detalhadamente as considerações dos autores, apresentase apenas as tabelas com os resultados dos tempos de processamento, seguidas de alguma conclusões importantes. O Gráfico 4, adiante, apresenta o resultado para implicaturas escalares diretas - enunciado (32a).

O ponto na parte esquerda inferior revela que os sujeitos levaram $3000 \mathrm{~ms}$ para escolher a figura aberta em (35b), caracterizando-se, portanto, como sujeitos que fizeram a leitura inferencial. $O$ ponto na parte direita superior revela que os sujeitos levaram quase $4000 \mathrm{~ms}$ para escolher a figura aberta em (35b). Já aqui uma primeira interpretação é possível. Comparando as escolhas entre a figura aberta condizente com a realização da inferência pragmática e a figura aberta que não condiz com a realização da inferência pragmática, percebe-se 
que o processamento da inferência leva menos tempo que a sua rejeição, resultado oposto ao produzido por Bott e Noveck (2004), segundo o qual implicaturas de quantidade exigem maior tempo de processamento.

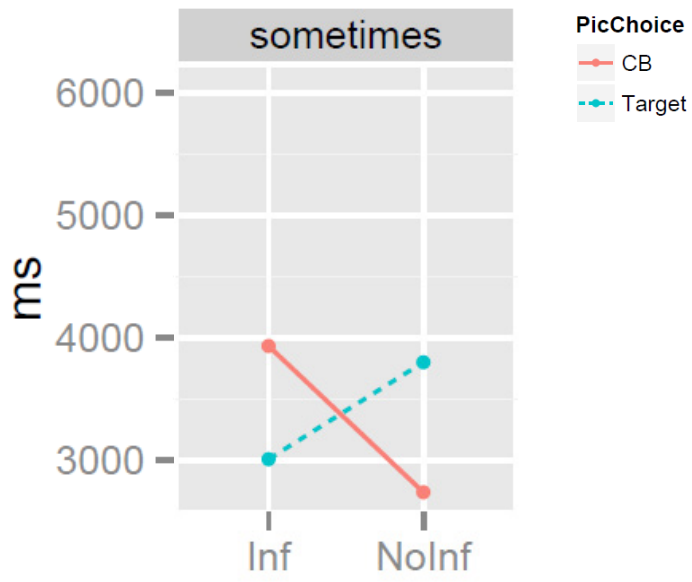

Gráfico 4. Tempos médios de resposta registrados no experimento 1 em Bill, Romoli e Schwarz (manuscrito)

O ponto na parte esquerda superior revela que os sujeitos levaram $4000 \mathrm{~ms}$ para escolher a caixa encoberta quando apresentados à figura aberta (34a). Aqui o sujeito apesar de realizar a inferência, razão pela qual escolhe a caixa encoberta, demora mais tempo que o sujeito que faz a inferência e pode escolher a figura aberta, provavelmente porque, no caso da escolha da caixa encoberta, uma primeira operação para a realização da inferência gere um conflito com a imagem, apenas solucionado subsequentemente pela escolha da caixa preta.

O ponto na parte direita inferior revela que os sujeitos levaram em torno de $3500 \mathrm{~ms}$ para escolher a caixa encoberta quando apresentados à figura aberta (34c). Aqui a escolha foi muito rápida porque a figura aberta (34c) deixa de satisfazer o conteúdo literal do enunciado (32a).

Todos esses resultados apontam para uma direção oposta àquela suposta em Bott e Noveck (2004). Enquanto este estudo demonstra que a interpretação de enunciados que disparam implicaturas escalares diretas é realizada mais lentamente por sujeitos que as consideram efetivas que por sujeitos que as desconsideram, o estudo de Bill, Romoli e Schwarz revela um padrão oposto. A tabela acima parece indicar agora que sujeitos que consideram as implicaturas efetivas processam os enunciados mais rapidamente que aqueles que estão dispostos a desconsiderá-las. Vale acrescentar ainda que Bill, Romoli e Schwarz obtiveram o mesmo tipo de resultado para implicaturas indiretas, revelando que o padrão de comportamento dos sujeitos permanece o mesmo, independente da polaridade dos enunciados testados.
Depois dos enunciados com implicaturas, Bill Romoli e Schwarz apresentam os resultados dos testes com pressuposições. Apresenta-se aqui o resultado do estudo para o teste de interpretação de pressuposições de enunciados como (35).

(35) João não parou de ir ao cinema na quarta.

No experimento sobre pressuposições, enunciados como (35) foram apresentados com imagens como (36a), $(36 b)$ e (36c)

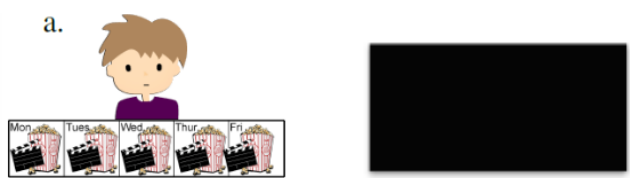

(36)
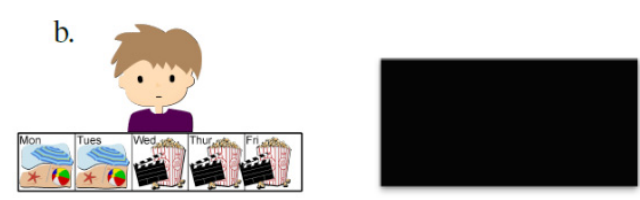

(36)

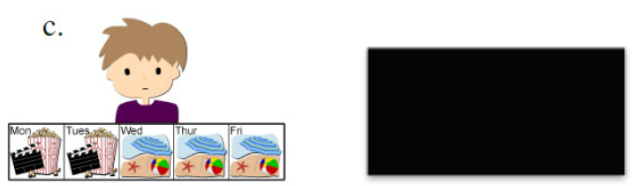

Em (36a) a figura aberta está de acordo com a asserção e a pressuposição de (35). Aqui a expectativa era a de grande número de escolhas da figura aberta, o que se confirmou. Em (36b), a figura aberta está de acordo com a asserção de (35), mas não com a pressuposição. Esse é o caso crítico, para o qual se esperava maior variação nas escolhas. Neste caso, a figura aberta teve escolha de $62 \%$. Em (36c), a figura aberta está de acordo com a pressuposição, mas não com a asserção. Neste caso, conforme o esperado, o índice de escolha foi baixo.

Os tempos de reação de cada uma das 4 possíveis escolhas esperadas (da figura aberta em a, da figura aberta ou da caixa encoberta em b e da caixa encoberta em c) são apresentados no Gráfico 5 a seguir.

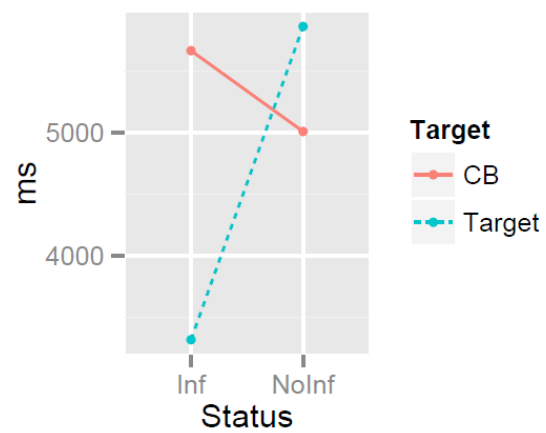

Gráfico 5. Tempos médios de resposta registrados no experimento 3 em Bill, Romoli e Schwarz (manuscrito) 
No Gráfico 5, o ponto à esquerda e embaixo registra o tempo de reação da escolha da figura aberta em (36a), mostrando que essa escolha, em que o sujeito tem a sua frente uma imagem que está de acordo com a asserção e a pressuposição, é feita em menos tempo que as demais (em menos de $3500 \mathrm{~ms}$ ). Já o ponto à direita e acima registra o tempo de reação da escolha da figura aberta em (36b), mostrando que a escolha por uma imagem condizente com a asserção, mas não com a pressuposição, é a que leva maior tempo para ser realizada. O ponto à esquerda e acima mostra o tempo médio de reação dos sujeitos que escolheram a caixa encoberta diante da imagem em (36b). Nesse caso, os sujeitos realizam a inferência pressuposicional, mas ao se depararem com uma imagem que com ela não condiz, parecem precisar de mais tempo para decidirem pela caixa encoberta. Por fim, o ponto à direita e embaixo mostra o tempo que os sujeitos levam para escolher a caixa preta diante da imagem (36c). Este é o resultado menos esperado, porque, mesmo seguindo um padrão similar dos gráficos das implicaturas, o tempo de processamento ainda parece demorado.

O resultado deste experimento com pressuposição está de acordo com os resultados de Bott e Chemla (2014), que indicaram um processamento rápido de pressuposições. Nessa mesma direção, o experimento de Bill, Romoli e Schwarz mostra que enunciados com pressuposições satisfeitas são processados mais rapidamente que os enunciados em que não são satisfeitas. A novidade, no entanto, está no resultado obtido com o conjunto dos dois experimentos, com implicaturas e pressuposições, já que os gráficos dos testes realizados com os dois tipos de inferências são bastante parecidos, mostrando que condições idênticas (satisfação ou não satisfação da inferência pela imagem apresentada como parâmetro para julgamento) afetam de modo similar os tempos de processamento. Em suma, os resultados desses experimentos mostrm que, em vez dos resultados discrepantes apresentados em (31), agora tem-se o resultado uniforme (37).

(37) Produção da implicatura ou da pressuposição < Não produção da implicatura ou da pressuposição

Esse resultado oferece algum suporte para a hipótese de Romoli, de que pressuposições são implicaturas escalares.

\section{Um estudo experimental com crianças: evidências para qual hipótese?}

Nas seções 6 e 7, foram apresentados trabalhos com resultados distintos quanto às características de processamento de implicaturas escalares e pressuposições por adultos. Essas pesquisas, que utilizaram o paradigma de julgamento de valor-de-verdade, revelaram diferenças de processamento de pressuposições e implicaturas, principalmente quanto ao tempo de processamento. Seus experimentos parecem indicar que pressuposições são processadas mais rapidamente que implicaturas, corroborando as hipóteses clássicas, para as quais tratase de fenômenos fundamentalmente distintos - sendo pressuposições disparadas por meio convencional e implicaturas geradas por processo conversacional de produção de sentido.

Romoli, juntamente com seus parceiros de pesquisa, tem, mais recentemente, realizado uma série de estudos experimentais usando um paradigma distinto: o paradigma de caixa encoberta. Para Romoli, esse paradigma parece se mais confiável. Um dos motivos seria o fato de que a disponibilização de uma figura aberta condizente apenas com o significado literal do enunciado-alvo daria mais liberdade de escolha ao sujeito da pesquisa, que, dessa forma, não se veria premido a realizar uma escolha radical entre verdadeiro e falso. Deixando a discussão sobre a confiabilidade dos modelos à parte, o fato é que os experimentos conduzidos por Romoli e seus parceiros entregaram resultados muito distintos daqueles produzidos por estudos anteriores. O que os novos estudos passaram a sugerir é que tanto pressuposições como implicaturas são processadas de modo similar. Um dos resultados interessantes foi o de que, nos dois casos, a escolha de uma figura que satisfaz a inferência leva menos tempo que a escolha da figura que não satisfaz (ou seja, que satisfaz apenas o sentido literal). Esse resultado estaria indicando que tanto implicaturas quanto pressuposições são inferências do mesmo tipo, o que seria evidência para a hipótese defendida em Romli (2015) de que pressuposições são, na verdade, implicaturas escalares obrigatórias.

Nem todas as evidências empíricas relativas a fenômenos pragmáticos são, contudo, contraditórias. Há, por exemplo, evidências bastantes regulares coletadas na literatura especializada - cf. Huang e Snedeker (2009), Noveck (2001) - de que crianças realizam com mais naturalidade a leitura literal (não inferencial) de enunciados que geram implicaturas escalares. Uma criança, por exemplo, parece admitir como correta uma sentença como (38) com muito mais naturalidade que um adulto.

(38) Alguns elefantes são mamíferos.

Considerando essa constatação feita pela literatura especializada, com a intenção de avaliar a validade da hipótese de que pressuposições são implicaturas escalares, Bill, Romoli e Schwarz (2016) apresenta um estudo 
avaliando a aceitação de enunciados com implicaturas e pressuposições com indivíduos de três grupos etários: crianças de 4 a 5 anos, crianças de 7 anos e adultos. A suposição dos autores foi a de que, se pressuposições são tipos de implicaturas e se crianças estão mais dispostas como demonstraram outros estudos - a aceitar enunciados com implicaturas não satisfeitas, então crianças estariam mais dispostas que adultos a aceitar enunciados com pressuposições não satisfeitas. Não foi isso, no entanto, que os resultados obtidos indicaram.

$\mathrm{O}$ experimento realizado pelos autores usou, mais uma vez, o paradigma da caixa encoberta. Os estímulos cruciais para as análises são dos tipos apresentados na Figura 1 seguir.

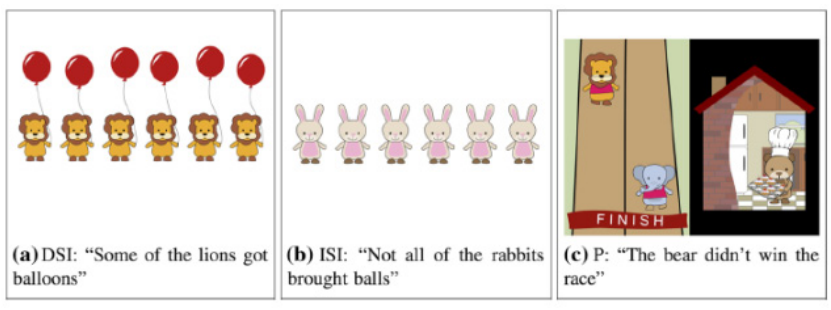

Figura 1. Estímulos visuais acompanhados das frases teste no experimento

Cada uma das figuras acima foi apresentada aos sujeitos ao lado de uma caixa encoberta e juntamente com um enunciado apresentado logo abaixo. Aqui, mais uma vez, a tarefa do sujeito era dizer, com base na observação da figura, se o enunciado apresentado era correto ou não. No primeiro caso, se o sujeito aceitasse o enunciado (de que alguns leões tinham balões) como uma descrição correta da figura, então estaria aceitando a leitura literal (não inferencial). O mesmo valia no caso da aceitação do enunciado (b) como uma descrição adequada da segunda figura. No caso da terceira figura, a aceitação do enunciado como uma descrição adequada também indicaria a realização da leitura literal (não literal). A expectativa dos pesquisadores, que procuravam corroborar a hipótese de Romoli (2014), era a de que tanto crianças como adultos tivessem índices de aceitação e rejeição similar para os três casos. Os resultados da investigação são apresentados no Gráfico 6 adiante.

O gráfico mostra, para cada um dos tipos de inferência (implicaturas escalares diretas, implicaturas escalares indiretas e pressuposições), a quantidade média de escolha da caixa encoberta nas situações de teste descritas acima, em que a figura não sustenta a inferência normalmente produzida pelo enunciado. Ou seja, o Gráfico 6 mostra os índices médios de rejeição entre os sujeitos investigados de cada faixa etária para cada tipo de enunciado na situação em que a inferência testada não é justificada pela figura apresentada. Esses índices revelam o grau de intolerância de cada grupo à violação de uma inferência.

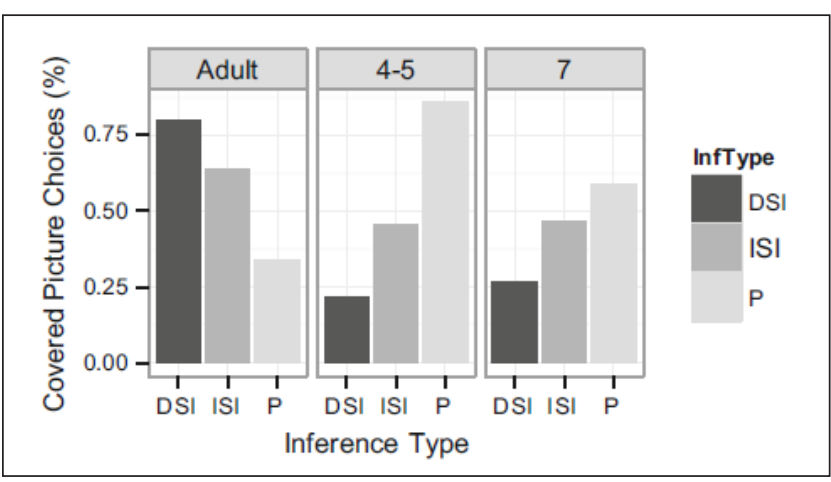

Gráfico 6. Tempos médios de resposta registrados em Bill, Romoli e Schwarz (2016)

Como se pode ver, os adultos se mostraram muito intolerantes à violação de implicaturas de quantidade diretas (com mais de $75 \%$ de rejeição), muito pouco tolerantes à violação de implicaturas de quantidade indiretas (com aproximadamente $60 \%$ de rejeição), mas bem mais tolerantes à violação de pressuposições (com pouco mais de $25 \%$ de rejeição). Já nos dois grupos de crianças os índices de intolerância seguem um padrão inverso. Crianças revelaram tolerar bem a violação e implicaturas escalares diretas (a intolerância dos dois grupos fica apenas em torno de $25 \%$ de rejeição), tolerar medianamente a violação e implicaturas escalares indiretas (a intolerância dos dois grupos fica em torno de $50 \%$ de rejeição). Em relação a pressuposições, os dois grupos de crianças mostraram tolerar menos sua violação que a de implicaturas, com destaque para o grupo de 4 a 5 anos, que apresentou um alto índice de rejeição (em torno de $80 \%$ ).

Contrariamente ao que esperavam os autores, esses resultados mostraram que, nos diferentes grupos etários, enunciados cujas implicaturas ou pressuposições não são justificadas pelas cenas que supostamente deveriam descrever são aceitos de modos muito distintos por cada grupo investigado. Assim, sem maiores considerações, esses resultados, de um modo ainda muito geral, oferecem maior suporte às hipóteses clássicas sobre a natureza de implicaturas e pressuposições. Nessa perspectiva, uma das explicações para a diferença de aceitação de implicaturas e pressuposições entre as crianças é a que toma como ponto de partida a suposição de que pressuposições são fenômeno convencional e implicatura, conversacional. Isso explicaria por que as crianças de 4 a 5 anos, ainda em uma etapa inicial do desenvolvimento de 
suas habilidades inferenciais, aceitam enunciados sem a produção da inferência normalmente a eles associadas por adultos. Já a violação de pressuposições, tradicionalmente vistas como resultado de marcação convencional, não seria aceita por crianças justamente pelo fato de que se trataria da violação de conteúdo mais próximo do sentido literal do enunciado, conteúdo produzido por mecanismo convencional e só sujeito a cancelamento através de operações inferenciais mais complexas.

Os adultos, por sua vez, já com suas habilidades inferenciais plenamente desenvolvidas, seriam menos tolerantes à interpretação apenas literal de enunciados com elementos geradores de implicaturas de quantidade. Entretanto, na perspectiva tradicional, seria necessário explicar por que adultos toleram mais a violação de pressuposições, o que não seria de se esperar, dado que, nessa perspectiva, conteúdos pressupostos resultam de uso de convenção, que costumam ser bastante resistentes a abalos de natureza contextual. De qualquer forma, um defensor da perspectiva tradicional poderia apelar para a suposição de que é justamente a maior capacidade inferencial que permitiria ao adulto reposicionar o escopo da negação em enunciados com gatilhos, ampliando-o para incluir em seu raio de ação os próprios conteúdos pressupostos.

Já Romoli e seus parceiros não se deram por vencidos. Para eles, se os resultados não ajudam a decidir entre as hipóteses concorrentes sobre a natureza de implicaturas escalares e pressuposições, também não chegam a falsificar a hipótese que defendem, a que assimila pressuposições a implicaturas. Suas considerações, bastante razoáveis, levam em consideração dois pressupostos teóricos. O primeiro, defendido em Romoli (2015), é o de que pressuposições são tipos especiais de implicaturas escalares: são implicaturas escalares obrigatórias. Nessa perspectiva, o cancelamento de pressuposições só seria aceito nas situações em que o intérprete se sentisse obrigado a considerar elementos contextuais que impedissem a produção do conteúdo inferido. Isso explicaria, para os autores, a tendência dos adultos de aceitar como bons enunciados como (39) diante da imagem (c) da Figura 1.

O urso não ganhou a corrida.

Nesse caso, o adulto, vendo que o urso não participou da corrida, teria elementos contextuais suficientes para reinterpretar o enunciado como significando que o urso não ganhou a corrida por não ter dela participado. Já a não aceitação das crianças é explicada pelos autores a partir da suposição adicional de que elas, no processo de interpretação, pelo menos até um certo ponto de seu desenvolvimento, não são capazes de considerar elementos contextuais em suas intepretações. Sendo assim, uma criança tenderia a ignorar a informação contextual representada pela figura vista e permaneceria presa à obrigatoriedade da produção da inferência.

Essas mesmas suposições explicariam, na visão dos autores, a diferença de aceitação, entre crianças e adultos, de enunciados com implicaturas que não se realizam. No caso dos adultos, a sua capacidade de considerar elementos contextuais, os levaria a considerar como parte do contexto que o produtor do enunciado (neste caso, o próprio pesquisador) não é ignorante quanto ao conteúdo da imagem na caixa encoberta. Sendo assim, o sujeito adulto tenderia a considerar que o produtor do enunciado com o item escalar alguns o estaria utilizando movido por saber que, na caixa encoberta, houvesse uma figura condizente com a inferência. Já no caso dos sujeitos dos grupos se 4 a 5 e de 7 anos, a mesma incapacidade inferencial que teria sido responsável pela manutenção da pressuposição (implicatura obrigatória) seria agora responsável pela desconsideração do contexto e a aceitação do enunciado como descrição da imagem aberta.

Evidentemente, os autores do estudo, em nome da hipótese que defendem, baseiam-se em suposições ainda sujeitas a algum questionamento. Não parece ponto pacífico, por exemplo, que um adulto que se submete a uma testagem, ciente da artificialidade da situação, vá tomar o pesquisador responsável pela elaboração do instrumento como um interlocutor típico, colaborativo a ponto de que possa considerá-lo comprometido com a existência de uma imagem real por trás da caixa encoberta. Ao contrário, espera-se que um adulto, no pleno exercício de suas capacidades inferenciais, perceba que o que se espera dele é uma decisão razoável com base apenas nos elementos visualmente disponíveis. De qualquer modo, esse é um ponto para discussão futura, que merece atenção e que pode, inclusive, determinar o modo de interpretar resultados obtidos em pesquisas experimenteis constituídas por tarefas de interpretação de enunciados.

\section{Considerações finais}

Estudos experimentais podem servir a variados propósitos. No interior do debate sobre a determinação mais precisa da natureza de fenômenos pragmáticos, a investigação da capacidade de processamento desses fenômenos por crianças, além de dizer muito sobre o desenvolvimento de aspectos cognitivos relevantes para o uso da linguagem verbal, pode colaborar de modo decisivo no processo de escolha entre modelos teóricos. Esse tipo de contribuição não é pequeno, uma vez que a compreensão dos processos envolvidos na produção de sentidos pode 
indicar caminhos de pesquisa antes inusitados, que, por sua vez, tendem a estabelecer novas demandas para a exploração experimental, configurando, no conjunto, um movimento de na direção de uma crescente compreensão dos processos cognitivos envolvidos no processamento da linguagem e do seu processo de maturação na mente humana.

Foi só recentemente que o debate na Pragmática Formal passou a valer-se de métodos experimentais como recurso auxiliar, a partir da consideração de aspectos relativos à plausibilidade empírica, para a confirmação de modelos teóricos abstratos acerca dos mecanismos de produção de sentido através do uso da linguagem verbal. Nesse curto espaço de tempo, no entanto, os estudos já realizados têm se revelado de grande valor, uma vez que, além de servirem à verificação de hipóteses, têm estimulado reformulações, agora não apenas preocupadas com a adequação descritiva, mas também com a adequação teórica dos modelos.

No que diz respeito ao debate sobre pressuposições, essa tendência tem sido muito fértil. Entre todos os fenômenos pragmáticos, talvez pressuposição possa ser considerado o mais controverso. Fenômeno pragmático, com origem usualmente atribuída ao uso de recursos formais convencionais, mas comportamento acentuadamente conversacional, pressuposição parece ter-se constituído numa espécie de quebra-cabeça teórico, com problemas descritivos e explanatórios desafiadores. Depois de algumas décadas de discussão, que assistiram à proposta de modelos teóricos dos mais variados tipos, alguns dos quais constituídos pelo ressurgimento de velhas convicções (como a ideia do terceiro valor-deverdade, que parece ressurgir nas teorias semânticas modernas sob a aparência de uma função parcial, que gera resultados indeterminados para determinados tipos de input linguístico), o apoio de resultados empíricos pode constituir-se como uma espécie de guia, de modo a auxiliar na escolha de caminhos teóricos mais sólidos em meio a uma profusão tão grande de recursos descritivos formais.

Nesse contexto, os estudos sobre o modo como indivíduos em fase de aquisição processam pressuposições são de fundamental importância. Entre tantas razões, há uma bastante importante. Sabe-se que grande parte de nossa compreensão necessita de habilidades que excedem em grande medida o simples domínio do código linguístico. Uma criança, mesmo sendo capaz de realizar operações sintáticas bastante refinadas em seu desempenho linguístico, pode não ter desenvolvido ainda a pleno certas habilidades cognitivas complexas, como o reconhecimento de intenções ou o reconhecimento de desejos e estados de crença alheios (Teoria da Mente). Sendo assim, formas distintas de processamento de enunciados com diferentes recursos formais (elementos de uma escala e gatilhos pressuposicionais, por exemplo) por crianças em uma idade que se caracterize pela carência de determinados recursos cognitivos constituem indicação forte não apenas de que os dois recursos considerados constituem fenômeno distinto, mas ainda fornecem pistas valiosas para a suposição de modelos descritivos adequados.

Este artigo procurou traçar, de modo bastante geral, o percurso de uma discussão atual sobre a natureza de dois fenômenos pragmáticos: implicaturas de quantidade escalares e pressuposições. Acompanhando esse percurso, percebe-se que dois paradigmas experimentais distintos produziram resultados em direções opostas. Diante desse quadro incerto, Bill, Romoli e Schwarz realizaram um estudo que se destaca por propor não uma mudança de paradigma, mas de alvo de investigação: crianças. Essa inovação trouxe resultados surpreendentes, capazes de dar fôlego a modelos mais tradicionais e de, adicionalmente, traçar limites para os modelos mais recentes. Revelaram, desse modo, a importância dos estudos experimentais voltados para a compreensão da aquisição de inferência pragmáticas não apenas para compreensão do desenvolvimento cognitivo da criança, mas também para o estabelecimento de bases mais sólidas para a elaborações de modelos teóricos formais em Pragmática.

\section{Referências}

ABUSCH, Dorit. Lexical alternatives as a source of pragmatic presuppositions. In: SALT XII, 2002, Ithaca. Proceedings. Ithaca, 2002. p. 1-19.

BILL, C.; ROMOLI, J.; SCHWARZ, F. Scalar implicatures versus presuppositions: The view from acquisition. Topoi, v. 35, n. 1, p. 57-71, 2016

BILL, C.; ROMOLI, J.; SCHWARZ, F. Are some presuppositions scalar implicatures? Assessing evidence from Reaction Times. (manuscrito)

BOTT, L.; NOVECK, I. A. Some utterances are underinformative: The onset and time course of scalar inferences. Journal of Memory and Language, v. 51, p. 437-457, 2004.

CHEMLA, E.; BOTT, L. Processing presuppositions: Dynamic semantics vs pragmatic enrichment. Language and cognitive processes, v. 28, n. 3, p. 241-260, 2013.

CHIERCHIA, G.; McCONNELL-GINET, S. Meaning and grammar. Massachussets: MIT, 1990.

CHIERCHIA, G.; FOX, D.; SPECTOR, B. Scalar implicatures as a grammatical phenomenon. In: MAIENBORN, C.; HEUSINGER, K. V.; PORTNER, P. Semantics: an international handbook of natural language meaning. Vol. 3. Göttingen: De Gruiter Mouton, 2012. p. 2297-2331.

HORN, L. A natural history of negation. Stanford: CSLI, 1989.

HUANG, Y. T.; SNEDEKER, J. Online interpretation of scalar quantifiers: Insight into the semantics-pragmatics interface. Cognitive Psychology, v. 58, p. 376-415, 2009. 
KAMP, H.; REYLE, U. From discourse to logic. Dordrecht: Kluwer, 1993.

LEVINSON, Stephen C. Presumptive meanings. Massachusetts: MIT, 2000.

NOVECK, I. A. When children are more logical than adults: experimental investigations of scalar implicature. Cognition, v. 78, p. 165-188, 2001.

OLIVEIRA, R. P.; BASSO, R. M. Arquitetura da conversação: teoria das implicaturas. São Paulo: Parábola, 2014.

ROMOLI, Jacopo. The presuppositions of soft triggers are not presuppositions. In: SALT 21., 2011, New Brunswick, Proceedings. New Brunswick: Rutgers University, 2011. p. 1-15.

ROMOLI, Jacopo. Soft but Strong: Neg-raising, soft triggers, and exhaustification. $267 \mathrm{f}$. Thesis - Harvard University, 2012 .
ROMOLI, Jacopo. The presuppositions of soft triggers are obligatory scalar implicatures. Journal of Semantics, v. 32, p. 173-219, 2015.

SAUERLAND, U. Scalar implicatures in complex sentences. Linguistics and Philosophy, v. 27, p. 367-391, 2004.

SIMONS, Mandy. On the conversational basis of some presuppositions. Semantics and Linguistic Theory (SALT 11), 2001.

SOAMES, Scott. How pressupositions are inherited: a solution to the projection problem. In: DAVIS, Steven. Pragmatics: a reader. Oxford: Oxford University Press, 1991. p. 428-470.

Recebido: 12 de março de 2017

Aprovado: 23 de maio de 2017

Contato:

Marcos Goldnadel <emegold@gmail.com> 